\title{
Developmental Changes in Conflict Resolution Styles in Parent-Adolescent Relationships: A Four-Wave Longitudinal Study
}

\author{
Muriel D. Van Doorn · Susan J. T. Branje • \\ Wim H. J. Meeus
}

Received: 17 December 2009/Accepted: 12 February 2010/Published online: 23 February 2010

(C) The Author(s) 2010. This article is published with open access at Springerlink.com

\begin{abstract}
In this study, changes in three conflict resolution styles in parent-adolescent relationships were investigated: positive problem solving, conflict engagement, and withdrawal. Questionnaires about these conflict resolution styles were completed by 314 early adolescents $(M=13.3$ years; $50.6 \%$ girls) and both parents for four consecutive years. Adolescents' reported use of positive problem solving increased with mothers, but did not change with fathers. Fathers reported an increase of positive problem solving with adolescents, whereas mothers reported no change. Adolescents' use of conflict engagement was found to temporarily increase with mothers, but showed no change with fathers. Mothers and fathers reported a decrease in conflict engagement with adolescents. Adolescents' use of withdrawal with parents increased, although this increase was temporarily with mothers. Mothers reported no change in withdrawal, whereas fathers' use of withdrawal increased. Generally, we found that both adolescents and their parents changed in their use of conflict resolution from early to middle adolescence. These results show that conflict resolution in parent-adolescent relationships gradually change in favor of a more horizontal relationship.
\end{abstract}

Keywords Conflict - Conflict resolution styles . Parent-adolescent relationships · Early adolescence . Development

M. D. Van Doorn $(\bowtie) \cdot$ S. J. T. Branje · W. H. J. Meeus Research Centre Adolescent Development, Utrecht University, P.O. Box 80.140, 3508 TC Utrecht, The Netherlands

e-mail: m.d.vandoorn@uu.nl

S. J. T. Branje

e-mail: s.j.t.branje@uu.nl

\section{Introduction}

Adolescence is a period in which many changes occur. Adolescents are striving for more autonomy and selfdetermination (Collins 1990; Laursen and Collins 2004). Indeed, one of the most salient developmental tasks during adolescence is establishing oneself as an autonomous being (Erikson 1959; Steinberg 1990). Ideally, parent-adolescent relationships in Western societies gradually change from a more vertical, asymmetrical relationship to a more horizontal, symmetrical relationship (Collins 1990, 1995; Collins and Steinberg 2006; Russell et al. 1998; Steinberg 1990; Youniss and Smollar 1985). Although parents encourage autonomy of their children and accept more symmetrical relations, they have somewhat different expectations regarding the timing of appropriate autonomy for their adolescents (Deković et al. 1997). These changes into more symmetrical relationships might therefore go hand in hand with some friction between parents and adolescents. In fact, conflicts are exceptionally suited to fostering the renegotiation of parental authority (Collins and Laursen 2004; Sillars et al. 2004; Smetana 1995) and are thus inevitable in this realignment process (Collins et al. 1997; Collins and Steinberg 2006). In the current study, we will investigate whether conflict resolution styles of adolescents and their parents change during adolescence.

Empirical studies have shown that conflict frequency and conflict intensity change during adolescence. For example, a meta-analysis showed that conflicts are most frequent during early adolescence and decline gradually thereafter (Laursen et al. 1998). Moreover, the same metaanalysis found that conflicts seem to be more intense during middle adolescence than during early adolescence. This latter finding has been confirmed by other researchers (De Goede et al. 2009; Jensen-Campbell and Graziano 2000). 
The combination of more frequent conflict during early adolescence, more intense conflicts during middle adolescence, and the gradual change into more symmetrical parent-adolescent relationships (De Goede et al. 2009) might be reflected by changes in the way adolescents and their parents handle conflicts with each other during this period (Collins and Laursen 2004). In this paper, we distinguish three different conflict resolution styles: positive problem solving, conflict engagement, and withdrawal. Positive problem solving involves trying to understand the other's position and using constructive reasoning to work out compromises. Conflict engagement involves being verbally abusive, angry, defensive or attacking, and losing self-control. Withdrawal involves avoiding the problem, avoiding to talk, and becoming distant (Kurdek 1994). In the current study, we will investigate whether adolescents and their parents change in their use of positive problem solving, conflict engagement, and withdrawal with each other from early to middle adolescence.

There are theoretical reasons to believe that the use of positive problem solving by adolescents and their parents change during adolescence. Several theorists argue that a more mature way of conflict resolution, characterized by more compromising and perspective taking, will develop in adolescence (e.g., Sandy and Cochran 2000; Selman 1980; Youniss and Smollar 1985). Due to developmental changes in perspective taking, adolescents will be increasingly able to simultaneously consider both their own and the other's perspective and may be able to use more mature styles of conflict resolution (Sandy and Cochran 2000). Moreover, in Western societies, the renegotiation process from a vertical parent-adolescent relationship into a more horizontal or egalitarian one starts in early adolescence (Collins and Laursen 2004; Russell et al. 1998). Therefore, we might expect that both adolescents and their parents will increase their use of positive problem solving. We suppose that parents also increasingly use positive problem solving in order to meet the new challenges of the parent-adolescent relationship and to allow the relationship to become more egalitarian. Empirical evidence for an increase in positive problem solving by adolescents during conflicts with parents is thin. Although a developmental metaanalysis on peer conflict resolution showed that negotiation and compromise increase during adolescence (Laursen et al. 2001), only one study investigated differences in positive problem solving in parent-adolescent relationships for two age groups and its results were rather mixed (Jensen-Campbell and Graziano 2000). This particular study found positive problem solving in daughter-mother relationships to be higher for older adolescents than for younger adolescents, but found the opposite for sonmother relationships and failed to find an effect of age with regard to adolescents' positive problem solving with fathers. Empirical evidence of changes in parental positive problem solving is still lacking. Thus, based on theory, positive problem solving of adolescents and their parents is supposed to increase from early to middle adolescence. However, this has not been consistently confirmed by empirical studies.

Theoretical ideas and empirical studies are inconsistent with respect to changes in conflict engagement by adolescents and their parents. From a developmental point of view, we might expect adolescents and their parents to decrease their use of conflict engagement during conflicts as this aggressive way of handling conflicts does not reflect developmental growth toward greater egalitarianism (Collins and Laursen 2004; Russell et al. 1998). That is, as adolescents grow older, a more equal power balance between adolescents and their parents evolves: adolescents will mature in their use of conflict resolution styles by more negotiation and less aggressive behaviour while at the same time parents are also providing more room for negotiation and are becoming less dominant during conflicts. However, empirical studies show a different pattern. For instance, the use of an aggressive conflict resolution style has been found to be higher for middle adolescents than for early adolescents (Tucker et al. 2003). Also, as has been mentioned before, empirical studies showed that conflict intensity increased from early to middle adolescence and then decline (De Goede et al. 2009; Jensen-Campbell and Graziano 2000; Laursen et al. 1998), which might be an indication that conflict resolution of adolescents is temporarily characterized by more fighting and arguing from early to middle adolescence. No empirical studies have yet been done on the development of this aggressive style by parents. In sum, based on several empirical studies, we expect an increase in conflict engagement by adolescents from early to middle adolescence.

With regard to the use of withdrawal during conflicts, we have several reasons to assume that withdrawal of adolescents increases from early to middle adolescence. First, the use of withdrawal often results in unresolved conflicts, which have been found to be more common in middle than in early adolescence (Smetana et al. 1991). Second, research on developmental changes in peer conflict resolution shows that the increase in compromising of adolescents is accompanied by an increase in disengagement or withdrawal as well, suggesting that adolescents might also learn to walk away from a conflict (Laursen et al. 2001). A similar pattern might apply for parentadolescent relationships and thus adolescents might also apply this strategy more often when facing conflicts with their parents as they get older. Therefore, we expect withdrawal by adolescents to increase from early to middle adolescence. We have no specific expectations with regard to withdrawal of parents. Thus, although theory and some 
empirical studies suggest that conflict resolution might change over time, longitudinal studies are clearly needed to draw conclusions about within-individual change. As close relationships are generally resistant to dramatic change (Laursen and Collins 1994), we chose to investigate parent-adolescent relationships for a period of 4 years. Relationships gradually change, and by incorporating a 4-year period, we should be able to discover change.

We chose to investigate changes in conflict resolution styles in adolescent-mother and adolescent-father relationships separately, not only because conflicts are mainly dyadic interactions, but most importantly because adolescents perceive their relationship with mothers and fathers differently (Youniss and Smollar 1985). For example, theories of parental complementarity in socialization imply that father-child interactions are less likely than motherchild interactions to be concerned with caregiving and intimate exchanges. In addition, several theoretical and empirical studies suggest that, during the transition to adolescence, mother-child interactions are characterized by greater perturbations than father-child interactions (Collins and Russell 1991). Among the explanations for this hypothesis is the greater amount of interaction of adolescents with mothers compared to fathers, and mothers' greater attempt to maintain children's dependency (e.g. Collins 1990; Collins and Russell 1991; Parke and Buriel 2006; Videon 2005). Although we have no clear theoretical or empirical reasons to expect differences between boys and girls, we will conduct preliminary analyses to examine whether we should incorporate this distinction in our main analyses.

\section{The Current Study}

With the current study, we investigated changes in conflict resolution styles of adolescents and their parents from early to middle adolescence. Before conducting our main analyses, we explored whether adolescents' sex was a factor that had to be taken into account. Subsequently, we examined the changes of each conflict resolution style separately. First, we investigated whether adolescents' reported level of positive problem solving with their parents increased from early to middle adolescence. Although empirical results are inconsistent (Jensen-Campbell and Graziano 2000), based on theory (Sandy and Cochran 2000; Selman 1980; Youniss and Smollar 1985), we hypothesized that adolescents' reported use of positive problem solving with their parents increased. We also expected an increase in parents' reported use of positive problem solving with adolescents. For adolescents' reported use of conflict engagement, based on previous research on aggressive conflict resolution and conflict intensity, we expected an increase in the use of this style by adolescents from early to middle adolescence (De Goede et al. 2009; Jensen-Campbell and Graziano 2000; Laursen et al. 1998; Tucker et al. 2003). We explored the use of parents' reported use of conflict engagement. Based on research on unresolved conflicts and on peer conflict resolution, we expected adolescents' use of withdrawal with parents to increase. We explored the use of parents' reported use of withdrawal. Finally, since we had no specific hypotheses about mean level differences in adolescents' and parents' reported conflict resolution styles, we investigated these in an explorative way.

\section{Method}

\section{Participants}

Participants in this 4-year longitudinal study were 314 families, including an early adolescent $(50.6 \%$ girls; $M=13.3$ years, $\mathrm{SD}=0.44$ ) and both parents. For the purposes of this study, we excluded adolescents who were not 13 or 14 years of age at the beginning of our study $(n=9)$. Data were collected with a 1-year interval between each of the waves. Adolescents named Dutch as their main ethnic identity and lived with both parents. The mean age of the fathers and mothers at Time 1 was respectively 46.82 years (ranging from 35 to $65, \mathrm{SD}=5.07$ ) and 44.10 years (ranging from 34 to 55 years, $\mathrm{SD}=4.23$ ). Different levels of education were represented, with approximately $49 \%$ of the adolescents at schools preparing for university, $34 \%$ of the adolescents at schools preparing for higher professional education and $17 \%$ of the adolescents at schools preparing for lower-level jobs. Of the fathers, $1.0 \%$ did not finish high school, $42.7 \%$ graduated from high school, $30.3 \%$ graduated from middle or higher level vocational/technical training, and $26.1 \%$ had a university degree. Of the mothers, $0.3 \%$ did not finish high school, $53.7 \%$ graduated from high school, $29.1 \%$ graduated from middle or higher level vocational/technical training, and $16.9 \%$ had a university degree.

The current sample, called the CONAMORE family sample (CONflict And Management Of Relationships; Meeus et al. 2004), is a subsample from an ongoing longitudinal study on relationships of adolescents with parents and friends. In the main study of CONAMORE, 938 early adolescents (mean age 12.4 years, $\mathrm{SD}=0.6$, ranging from 10 to 15 years) and 393 middle adolescents (mean age 16.7 years, $\mathrm{SD}=0.8$, ranging from 16 to 20 years) from various high schools located in the province of Utrecht, The Netherlands, annually filled out a battery of questionnaires at school. The family sample was selected as follows. First, at the first measurement of the main study, 
the Dutch early adolescents received a letter including an invitation to participate with both parents during annual home-visits as well. Of the families invited, 491 families initially agreed to participate. Second, due to our restriction of including only two-parent Dutch families, 90 one-parent families who agreed to participate were not able to take part in this additional research project. Finally, for financial reasons, 323 families were randomly selected from the 401 two-parent families to participate in the longitudinal study. When family members did not participate a particular year, they were asked again next year. The number of adolescents, fathers, and mothers who participated differed each year, but every year there was a participation rate of at least 95\%. Missing values (2\%) were estimated in Mplus using full information maximum likelihood, a procedure that generates unbiased estimates (Enders and Bandalos 2001). In the adolescent-mother dyads, there was one case with missing data on all variables, so this case was excluded from the adolescent-mother analyses.

\section{Procedure}

The participating adolescents were recruited from various, randomly selected schools in the province of Utrecht, The Netherlands. Of the schools that were approached, $60 \%$ decided to participate. Participants and their parents received an invitation letter, describing the research project and goals, and explaining the possibility to decline from participation. More than $99 \%$ of the approached high school students decided to participate. If the adolescent wished to participate, they (as well as their parents) were required to provide written informed consent. Data collection took place each year in the months of November and December. Interviewers visited the schools and asked participating adolescents to gather in classrooms to fill out a questionnaire. Interviewers also visited the families at home. During these home visits, adolescents filled out an additional questionnaire and both parents also filled out a questionnaire. The adolescents and their parents were instructed to fill out the questionnaire independently of each other. Confidentiality was guaranteed. Families received $€ 27$ for participation (approximately US \$36) and adolescents received an additional amount of $€ 10$ for participating at school (approximately US \$13).

\section{Measures}

\section{Conflict Resolution Styles}

Conflict resolution styles were measured using Kurdek's Conflict Resolution Style Inventory (CRSI; Kurdek 1994). This questionnaire, originally designed for couples, was modified so that it referred to parents and adolescents. The validity of this measure with regard to parent-adolescent relationships has been showed in various studies (Branje et al. 2009; Van Doorn et al. 2007, 2008). Three conflict resolution styles were used in this study: positive problem solving, conflict engagement, and withdrawal. Adolescents were asked to rate the extent to which they use these three conflict resolution styles when they have conflicts with fathers and mothers. Also, fathers and mothers were asked to rate the extent to which they used the same three conflict resolution styles when they have conflicts with their adolescents. Thus, each person reported on one's own conflict resolution style. Each conflict resolution style was measured by 5 items and the items were rated on a 5-point Likert scale with response options ranging from never to always. Positive problem solving involved making compromises and discussing the conflict effectively. Sample items of positive problem solving were: "negotiating and trying to find a solution that is mutually acceptable" and "sitting down and discussing the differences of opinion". Conflict engagement involved being verbally abusive, getting very angry, or losing self-control and was measured by items such as: "getting furious and losing my temper", and "letting myself go and saying things I do not really mean". Withdrawal implied avoiding the problem, avoid talking, and becoming distant. Items used to measure withdrawal were for example: "not listening anymore", "refusing to talk any longer", and "withdrawing from the situation".

Factor analyses on Time 1 showed the expected threefactor structure for adolescent-mother (all loadings $>.43$ on the relevant factor), adolescent-father (all loadings $>.44$ on the relevant factor), mother-adolescent (all loadings $>.40$ on the relevant factor), and father-adolescent conflict resolution styles (all loadings $>.42$ on the relevant factor). This factor structure has also been found by Kurdek (1994), with regard to the marital relationship. The stability of the conflict resolution styles over a 1 year period throughout Time 1 to 4 was moderately high, ranging from .53 to .73 in the adolescent-parent relationship, and from .44 to .73 in the parent-adolescent relationship, respectively. Cronbach's alphas of the subscales conflict engagement, withdrawal, and positive problem solving on Time 1 ranged from .77 to .84 for adolescents' conflict resolution with mothers, from .80 to .90 for adolescents' conflict resolution with fathers, from .68 to .80 for mothers' conflict resolution with adolescents, and from .69 to .78 for fathers' conflict resolution with adolescents, indicating sufficient internal consistency of these scales (Henson 2001).

Finally, analyses were undertaken to assure that the scaling of participants across relationships was comparable. To investigate whether this was the case, we performed multigroup confirmatory factor analyses using Mplus 
(Muthén and Muthén 1998-2007). A model with factor loadings constrained to be equal across the four groups (adolescent-mother, adolescent-father, mother-adolescent, and father-adolescent reports) on the three conflict resolution styles (positive problem solving, conflict engagement, and withdrawal) was compared to a model with all factor loadings being free across the groups. We used the Chi-square difference test, change in CFI and TLI, and change in RMSEA as indicators of a change in fit, with relatively lower RMSEA's and higher CFI's/TLI's indicating better fit (Kline 2005). With regard to change in CFI, TLI, and RMSEA a decrease of .01 on these measures can be regarded as substantial (Chen 2007). The model wherein the factor loadings were constrained to be equal across the groups provided a good fit to the data: $\chi^{2}(384)=693.40$, $p<.01, \mathrm{CFI}=.95$, TLI $=.94$ and RMSEA $=.05$. The Chi-square difference test revealed that the model wherein the factor loadings were free to vary across the groups provided a significantly better fit to the data: $\Delta \mathrm{Chi}^{2}$ (35) $=76.36, p<.01$. However, differences in CFI, TLI, and RMSEA were not significantly different for the two models $(\triangle \mathrm{CFI} / \mathrm{TLI}=.007$ and .002 , respectively, and $\triangle$ RMSEA $=.00$ ). Thus, the combination of measures led to the conclusion that the model wherein the factor loadings were constrained to be equal across groups was not meaningfully different from the model wherein the factor loadings were free to vary across the groups.

\section{Results}

\section{Descriptives and Correlations}

The means and standard deviations of the variables used in the current study are shown in Table 1. Correlations between conflict resolution styles of adolescents with parents and parents with adolescents at Time 1 are presented in Table 2. Generally, we found that the use of conflict resolution styles by adolescents with their parents was significantly related to the use of the same conflict resolution styles by their parents ( $r$ ranged from .11 to .26, $p<.05$, with one exception of $.08, n s)$. Moreover, Table 2 shows that the use of conflict engagement by one person was significantly related to the use of withdrawal by the same person ( $r$ ranged from .38 to $.47, p<.01$ ). We also computed Pearson correlations between conflict resolution in the adolescent-father and adolescent-mother relationship. Positive problem solving of adolescents with fathers and mothers was highly related within waves ( $r$ ranged from .70 to $.75, p<.01$ ), indicating that when adolescents use more positive problem solving with fathers they also use more positive problem solving with mothers. The same was true for conflict engagement of adolescents ( $r$ ranged
Table 1 Means and standard deviations of the conflict resolution styles in parent-adolescent relationships

\begin{tabular}{|c|c|c|c|c|}
\hline & $\begin{array}{l}\text { Time } 1 \\
M \text { (SD) }\end{array}$ & $\begin{array}{l}\text { Time } 2 \\
M \text { (SD) }\end{array}$ & $\begin{array}{l}\text { Time } 3 \\
M \text { (SD) }\end{array}$ & $\begin{array}{l}\text { Time } 4 \\
M \text { (SD) }\end{array}$ \\
\hline \multicolumn{5}{|c|}{ Positive problem solving } \\
\hline $\begin{array}{l}\text { Adolescent- } \\
\text { mother }\end{array}$ & $3.15(.90)$ & $3.16(.92)$ & $3.27(.86)$ & $3.33(.83)$ \\
\hline Adolescent-father & $3.01(.98)$ & $3.00(1.02)$ & $3.07(1.00)$ & $3.20(.93)$ \\
\hline Mother-adolescent & $4.03(.54)$ & $4.01(.55)$ & $3.98(.58)$ & $3.99(.54)$ \\
\hline Father-adolescent & $3.64(.60)$ & $3.62(.63)$ & $3.68(.56)$ & $3.72(.54)$ \\
\hline \multicolumn{5}{|l|}{ Conflict engagement } \\
\hline $\begin{array}{l}\text { Adolescent- } \\
\text { mother }\end{array}$ & $1.44(.55)$ & $1.48(.54)$ & $1.48(.58)$ & $1.41(.51)$ \\
\hline Adolescent-father & $1.32(.50)$ & $1.31(.49)$ & $1.39(.60)$ & $1.33(.51)$ \\
\hline Mother-adolescent & $1.76(.50)$ & $1.69(.47)$ & $1.67(.47)$ & $1.61(.48)$ \\
\hline Father-adolescent & $1.72(.48)$ & $1.69(.50)$ & $1.67(.51)$ & $1.62(.52)$ \\
\hline \multicolumn{5}{|l|}{ Withdrawal } \\
\hline $\begin{array}{l}\text { Adolescent- } \\
\text { mother }\end{array}$ & $1.96(.71)$ & $2.06(.79)$ & $2.05(.79)$ & $1.97(.78)$ \\
\hline Adolescent-father & $1.83(.78)$ & $1.88(.84)$ & $1.95(.84)$ & $1.93(.84)$ \\
\hline Mother-adolescent & $1.59(.54)$ & $1.63(.53)$ & $1.59(.52)$ & $1.60(.58)$ \\
\hline Father-adolescent & $1.64(.55)$ & $1.67(.55)$ & $1.67(.53)$ & $1.71(.61)$ \\
\hline
\end{tabular}

from .71 to .77, $p<.01$ ) and for withdrawal ( $r$ ranged from .72 to $.78, p<.01$ ). Positive problem solving of fathers and mothers with adolescents was also significantly correlated within waves, but this correlation was lower than the correlation between positive problem solving of adolescents with fathers and mothers ( $r$ ranged from .11 to .22, $p<.05$ ). The same was true for conflict engagement of fathers and mothers ( $r$ ranged from .22 to $.33, p<.001$ ) and for withdrawal ( $r$ ranged from .23 to $.26, p<.001$ ). Thus, the use of a certain conflict resolution style by adolescents with fathers and mothers was highly related within waves, whereas levels of conflict resolution styles across mothers and father co-varied only to a small degree.

\section{Preliminary Analyses on Differences}

in the Development of Conflict Resolution

Styles for Boys and Girls

Before investigating adolescents' and parents' change over time in conflict resolution styles, we tested whether there were differences between boys and girls on the development of the conflict resolution styles with their parents. Repeated measures ANOVAs with levels of the conflict resolution styles at Time 1 to 4 as within subject measure and adolescents' sex as between subject factor showed that there were no interaction effects. There were four occasions in which the scores of girls and boys on the conflict resolution styles with fathers or mothers were significantly different from each other. Thus, there were some differences between boys 
Table 2 Time 1 correlations between conflict resolution styles of adolescents with parents and parents with adolescents

\begin{tabular}{lccccc}
\hline & ps a-p & ce a-p & wi a-p & ps p-a & ce p-a \\
\hline Positive problem solving a-p & - & $-.13^{*}$ & $-.22^{* *}$ & $.11^{*}$ & -.01 \\
Conflict engagement a-p & -.07 & - & $.47^{* *}$ & -.02 & $.13^{*}$ \\
Withdrawal a-p & $-.19^{* *}$ & $.47^{* *}$ & - & -.02 & -.03 \\
Positive problem solving p-a & .08 & -.06 & -.07 & - & $.13^{* *}$ \\
Conflict engagement p-a & -.03 & $.19 * *$ & .08 & -.08 & -.11 \\
Withdrawal p-a & .05 & $.25^{* *}$ & $.26^{* *}$ & -.08 & $-.13^{*}$ \\
\hline
\end{tabular}

Note: $p s$ positive problem solving, $c e$ conflict engagement, $w i$ withdrawal, $a-p$ adolescents' conflict resolution with parents, $p$ - $a$ parents' conflict resolution with adolescents. Correlations below the diagonal involve adolescent-mother relationships and correlations above the diagonal involve adolescent-father relationships

$* p<.05, * * p<.01$

and girls in their reported use of the three conflict resolution styles with fathers and mothers, but adolescents' reported change in their use of the three conflict resolution styles with fathers and mothers was comparable for boys and girls. Therefore, boys and girls were analyzed as one group.

Development of Conflict Resolution Styles

in Parent-Adolescent Relationships

To investigate adolescents' and parents' change over time in positive problem solving, conflict engagement, and withdrawal, we performed 12 univariate latent growth models using Mplus (Muthén and Muthén 1998-2007). For each conflict resolution style, a model was tested for adolescent-mother, adolescent-father, mother-adolescent, and father-adolescent relationships separately, resulting in a total of 12 models: $2 \times 3$ styles of adolescents with parents (mothers/fathers) and $2 \times 3$ styles of parents (mothers/ fathers) with adolescents. We first tested a linear model. When the mean or variance of the quadratic slope was significant, we used the model with the quadratic slope. When the mean and variance of the quadratic slope were both not significant, we used the model with the linear slope. To evaluate the fit of each model, we used the Comparative Fit Index (CFI), the Tucker-Lewis Index (TLI), and the Root Mean Square Error of Approximation (RMSEA). For values of CFI and TLI, values above .90 indicate acceptable fit and values above .95 indicate good fit ( $\mathrm{Hu}$ and Bentler 1999). RMSEA values up to .05 represent an acceptable fit of the model (Bollen 1989).

In four out of twelve models, we found that the model with the quadratic slope fitted the data better than the model with the linear slope only (see Table 3 ). The models fitted the data sufficiently both for adolescent-mother relationships (CFI's range from .98 to 1.00 , TLI's range from .98 to 1.00 , and RMSEA's were .00 , with one exception of .06) and adolescent-father relationships (CFI's range from .96 to 1.00, TLI's range from .96 to 1.00 , and RMSEA's range from .00 to .04 , with two exceptions of .07). Table 3 shows the intercepts and slopes of positive problem solving, conflict engagement, and withdrawal of adolescents and parents. In Figs. 1, 2, and 3, changes in conflict resolution styles of adolescents and parents are shown. Note that the y-axis range is different for the three conflict resolution styles for presentation clarity purposes.

\section{Changes in Adolescents' and Parents' Use of Positive Problem Solving}

We hypothesized that positive problem solving of adolescents with parents would increase from early to middle adolescence. We found that, whereas adolescents' reported use of positive problem solving with mothers increased from early to middle adolescence, adolescents' reported use of positive problem solving with fathers did not change on average. We also hypothesized that parents' use of positive problem solving with adolescents would increase from early to middle adolescence. However, positive problem solving of mothers with adolescents did not change on average. Fathers' reported use of positive problem solving with adolescents did indeed increase.

\section{Changes in Adolescents' and Parents' Use of Conflict Engagement}

Partly confirming our hypothesis, we found that changes in adolescents' reported use of conflict engagement with mothers was curvilinear: conflict engagement increased between Time 1 and Time 2, and decreased between Time 2 and Time 4. Thus, we did find an increase in adolescents' reported use of conflict engagement with mothers, but this increase was only temporary. Unexpectedly, adolescents' use of conflict engagement with fathers did not change on average. We explored the use of conflict engagement by parents and found conflict engagement of both mothers and fathers to decrease significantly over time. 
Table 3 Adolescents' and parents' change over time in conflict resolution styles

\begin{tabular}{|c|c|c|c|c|c|c|c|c|c|c|c|c|c|}
\hline & \multicolumn{5}{|l|}{ Intercept } & \multicolumn{4}{|c|}{ Linear slope } & \multicolumn{4}{|c|}{ Quadratic slope } \\
\hline & $M$ & $95 \% \mathrm{CI}$ & SE & $\sigma^{2}$ & SE & $M$ & SE & $\sigma^{2}$ & SE & $M$ & SE & $\sigma^{2}$ & SE \\
\hline \multicolumn{14}{|c|}{ Positive problem solving } \\
\hline Adolescent-mother & $3.13 * * * \mathrm{~d}$ & $3.03-3.23$ & .05 & $.51 * * *$ & .07 & $.06 * * *$ & .02 & .02 & .01 & & & & \\
\hline Adolescent-father & $3.01 * * * \mathrm{~d}$ & $2.90-3.12$ & .06 & $.85 * * *$ & .15 & -.04 & .06 & $.56 * *$ & .19 & .03 & .02 & $.05 * * *$ & .01 \\
\hline Mother-adolescent & $4.02 * * *^{\mathrm{f}}$ & $3.96-4.08$ & .03 & $.16 * * *$ & .02 & -.01 & .01 & .00 & .00 & & & & \\
\hline Father-adolescent & $3.62 * * * \mathrm{e}$ & $3.56-3.68$ & .03 & $.22 * * *$ & .04 & $.03 * *$ & .01 & .01 & .01 & & & & \\
\hline \multicolumn{14}{|l|}{ Conflict engagement } \\
\hline Adolescent-mother & $1.44 * * *^{\mathrm{a}}$ & $1.38-1.50$ & .03 & $.20 * * *$ & .03 & $.07 *$ & .03 & .00 & .00 & $-.03 * *$ & .01 & $.00 * * *$ & .00 \\
\hline Adolescent-father & $1.31 * * * \mathrm{a}$ & $1.26-1.37$ & .03 & $.15^{* * *}$ & .02 & .04 & .03 & .00 & .00 & -.01 & .01 & $.00 * * *$ & .00 \\
\hline Mother-adolescent & $1.75 * * * b c$ & $1.70-1.80$ & .03 & $.18 * * *$ & .02 & $-.04 * * *$ & .01 & $.01 * *$ & .00 & & & & \\
\hline Father-adolescent & $1.72 * * * \mathrm{bc}$ & $1.67-1.78$ & .03 & $.17 * * *$ & .02 & $-.03 * * *$ & .01 & .00 & .00 & & & & \\
\hline \multicolumn{14}{|l|}{ Withdrawal } \\
\hline Adolescent-mother & $1.97 * * * \mathrm{c}$ & $1.89-2.05$ & .04 & $.28 * *$ & .09 & $.13^{* *}$ & .05 & .08 & .13 & $-.05 * *$ & .01 & .01 & .01 \\
\hline Adolescent-father & $1.84 * * * \mathrm{c}$ & $1.76-1.92$ & .04 & $.42 * * *$ & .06 & $.04 *$ & .02 & $.03 * *$ & .01 & & & & \\
\hline Mother-adolescent & $1.61 * * * \mathrm{~b}$ & $1.55-1.66$ & .03 & $.17 * * *$ & .02 & .00 & .01 & $.01 *$ & .00 & & & & \\
\hline Father-adolescent & $1.64 * * * b$ & $1.58-1.70$ & .03 & $.19 * * *$ & .02 & $.02 *$ & .01 & .00 & .00 & & & & \\
\hline
\end{tabular}

Note: Differing superscript alphabets indicate significant differences between the intercepts within adolescent-mother and adolescent-father relationships

$* p<.05, * * p<.01, * * * p<.001$

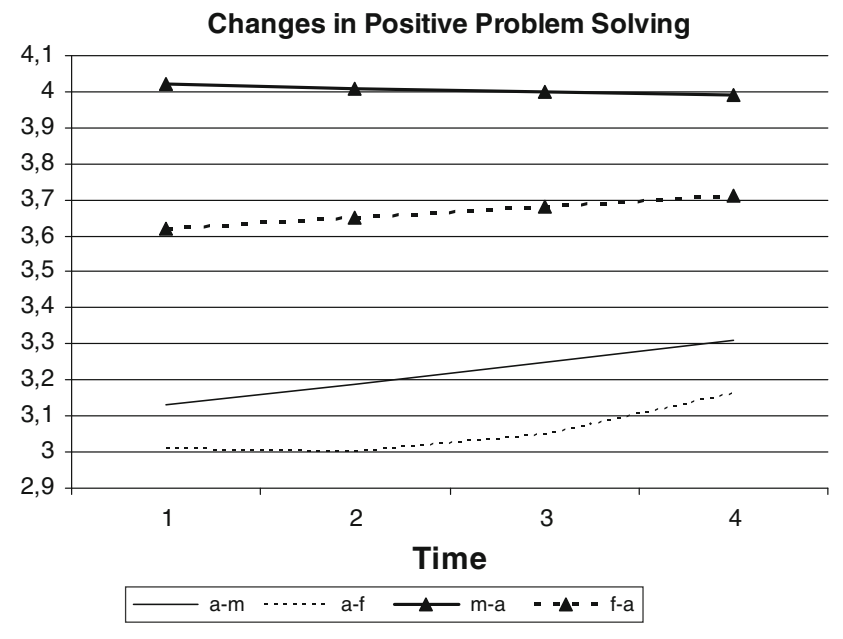

Fig. 1 Changes in positive problem solving in parent-adolescent relationships. A-m = adolescents' reported use of positive problem solving with mothers, a-f $=$ adolescents' reported use of positive problem solving with fathers, $\mathrm{m}-\mathrm{a}=$ mothers' reported use of positive problem solving with adolescents, $\mathrm{f}-\mathrm{a}=$ fathers' reported use of positive problem solving with adolescents

\section{Changes in Adolescents' and Parents' Use of Withdrawal}

As expected, withdrawal by adolescents with both parents was found to increase, although the increase of adolescents' use of withdrawal with mothers was only temporarily: adolescents' use of withdrawal increased between Time 1 and Time 2, and decreased between Time 2 and Time 4. Mothers' use of withdrawal did not change, on

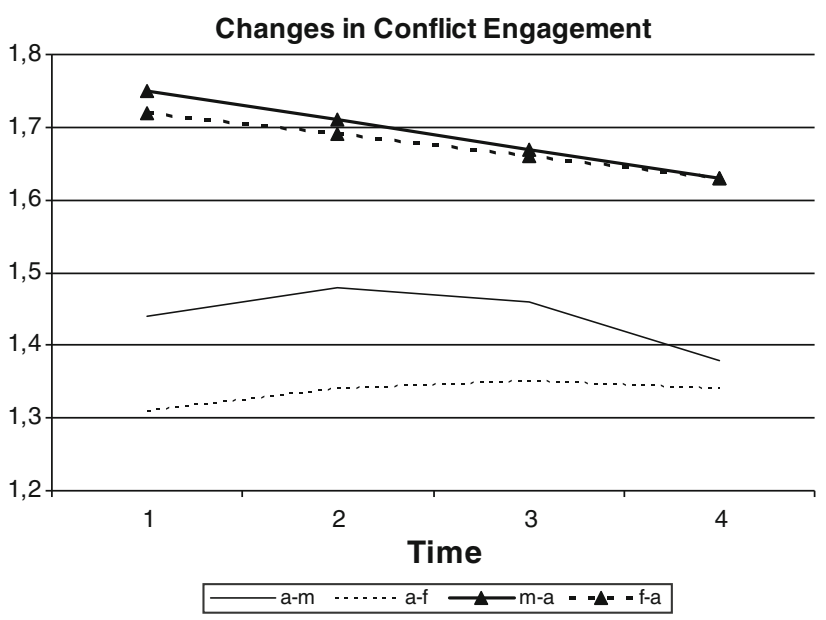

Fig. 2 Changes in conflict engagement in parent-adolescent relationships. A-m = adolescents' reported use of conflict engagement with mothers, a-f $=$ adolescents' reported use of conflict engagement with fathers, $\mathrm{m}-\mathrm{a}=$ mothers' reported use of conflict engagement with adolescents, $\mathrm{f}-\mathrm{a}=$ fathers' reported use of conflict engagement with adolescents

average, and fathers' use of withdrawal was found to significantly increase from early to middle adolescence.

Mean Level Differences in Adolescents' and Parents' Reported Conflict Resolution Styles

Table 3 shows that in each dyad the reported use of positive problem solving was significantly higher than the 


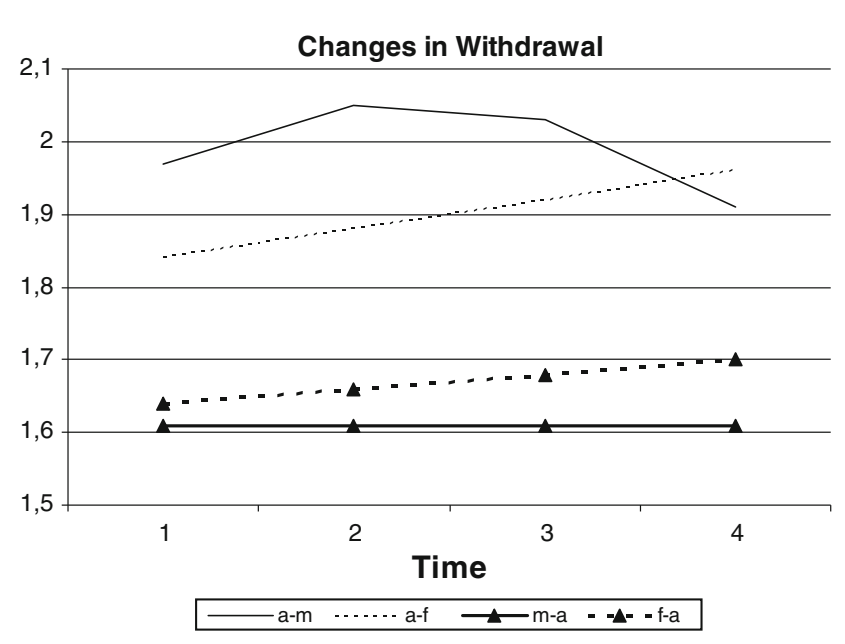

Fig. 3 Changes in withdrawal in parent-adolescent relationships. A- $m=$ adolescents' reported use of withdrawal with mothers, a-f $=$ adolescents' reported use of withdrawal with fathers, $\mathrm{m}-\mathrm{a}=$ mothers' reported use of withdrawal with adolescents, $\mathrm{f}-\mathrm{a}=$ fathers' reported use of withdrawal with adolescents

reported use of conflict engagement and withdrawal. Furthermore, confidence intervals showed that, in parentadolescent relationships, adolescents' reported level of withdrawal was higher than adolescents' reported level of conflict engagement. In contrast, the reported use of conflict engagement and withdrawal by parents did not differ. With respect to positive problem solving, parents reported significantly higher levels of this style compared to adolescents. Moreover, mothers reported higher levels of positive problem solving than fathers. Adolescents used similar levels of positive problem solving towards their mothers and fathers. Parents' reported use of conflict engagement with adolescents was also higher than adolescents' reported use of conflict engagement with parents. Mothers and fathers used similar levels of conflict engagement towards their adolescents and adolescents used similar levels of conflict engagement towards their mothers and fathers. Finally, with respect to withdrawal, Table 3 showed that adolescents reported significantly higher levels of withdrawal towards their parents than their parents towards them. Mothers and fathers used similar levels of withdrawal towards their adolescents and adolescents used similar levels of withdrawal towards their mothers and fathers.

In sum, we found some mean level differences in adolescents' and parents' reported conflict resolution styles: parents reported significantly higher levels of positive problem solving and conflict engagement towards adolescents than adolescents, whereas adolescents reported significantly higher levels of withdrawal towards their parents than their parents. In general, mothers and fathers did not differ in the reported levels of the conflict resolution styles towards adolescents (except for positive problem solving, for which mothers reported higher levels than fathers), and adolescents reported similar levels of the conflict resolution styles towards mothers and fathers.

\section{Discussion}

The purpose of the present study was to investigate changes in conflict resolution styles in parent-adolescent relationships. Generally, we found that both adolescents and their parents changed in their use of conflict resolution from early to middle adolescence in favor of a more horizontal and symmetrical relationship, as indicated by changes in both positive problem solving and conflict engagement. We found some differences in the development of adolescents' conflict resolution styles with their mothers and fathers. In addition, the development of parents' reported conflict resolution styles with their adolescents was also in some instances different for mothers and fathers.

In line with theoretical arguments that more mature ways of conflict resolution develop during adolescence (Sandy and Cochran 2000; Selman 1980; Youniss and Smollar 1985), we found that adolescents reported an increase in their use of positive problem solving with mothers from early to middle adolescence. However, adolescents' reported use of positive problem solving with fathers did not change. The finding that adolescents reported an increase in their use of positive problem solving with mothers and not with fathers is somewhat in line with the Jensen-Campbell and Graziano study (2000), which found an increase in compromising only in daughter-mother relationships, not in son-mother and adolescent-father relationships. Whereas mothers' reported use of positive problem solving with adolescents did not change on average, fathers' reported use of positive problem solving significantly increased. However, as mothers reported significantly higher levels of initial positive problem solving towards adolescents than fathers in early adolescence, the increase in positive problem solving of fathers should be interpreted carefully. The results with respect to positive problem solving suggest that there is more maturation in adolescents' relationship with mothers and that fathers are lagging behind. However, the increase of fathers' reported positive problem solving might suggest that fathers might catch up eventually. This is an area for future investigation.

Adolescents' reported use of conflict engagement with mothers first increased and then decreased around middle adolescence. We found no change in adolescents' reported use of conflict engagement with fathers. Thus, although previous research found an increase in aggressive conflict resolution of adolescents with both mothers and fathers 
(Tucker et al. 2003), we only found that adolescents' reported use of conflict engagement with mothers increased and this increase was temporary. The self-reported use of conflict engagement by both mothers and fathers was found to decrease. Thus, both parents report that they use this aggressive style to a lesser extent over time, suggesting that parents also change the way that they handle conflicts with their adolescents in line with the demands of a more symmetrical relationship. Overall, our results seem to imply that-especially in adolescent-mother relationships-adolescents are using more mature ways and less aggressive ways of handling conflict around mid-adolescence. However, this does not mean that the realignment and maturation of adolescent-mother relationships go smoothly, as we found that the use of conflict engagement of adolescents with mothers temporarily increased. The realignment process with fathers might be just less turbulent. Another explanation for the fact that we found fewer changes in the way adolescents handle conflicts with their fathers is that there are also fewer conflicts and thus fewer opportunities to experiment and grow in conflict resolution (Collins and Laursen 2004; Collins et al. 1997; Laursen 1995).

With respect to withdrawal, we found that adolescents' reported level of withdrawal with both parents increased, although the increase with mothers was only temporary. This is in line with an earlier study that found that unresolved conflicts, which are often the outcome when withdrawal is applied during conflicts, are more common in middle than in early adolescence (Smetana et al. 1991). As adolescents have been found to decrease their disclosure levels during adolescence (Keijsers et al. 2009), the (temporal) increase in adolescents' reported use of withdrawal with parents might even be a subtle indication of increasing autonomy of the adolescent. Moreover, our study showed that, whereas mothers' reported use of withdrawal did not change, fathers' reported use of withdrawal significantly increased. This might be explained by the differential roles fathers and mothers play in their adolescents' lives. For example, mothers spend more time in caregiving, joint activities, and conversation with their adolescents than fathers do (Lewis and Lamb 2003; Parke and Buriel 2006; Youniss and Smollar 1985), know more about their adolescents' activities than fathers (Waizenhofer et al. 2004), and-presumably as a result - have more conflicts with them than fathers have (Collins and Laursen 2004; Collins et al. 1997; Laursen 1995). Also, the relationship between adolescents and fathers is typically more distant than the relationship between adolescents and mothers. Therefore, the development of a new, more mature way of conflict resolution might be necessary at an earlier point in time for adolescentmother relationships than for adolescent-father relationships. An alternative interpretation of our findings regarding the differences in positive problem solving and withdrawal by mothers and fathers may be due to stereotype gender differences in managing relationships. For instance, positive problem solving might include more feminine behaviors, such as collaboration, listening, and greater verbal communication, whereas withdrawal is a more stereotypically masculine characteristic (Christensen and Heavey 1990). This might explain the higher levels of positive problem solving by mothers compared to fathers and why fathers are increasingly using withdrawal from early to middle adolescence. Perhaps when parent-adolescent relationships change into more horizontal relationships that are more and more characterized by greater egalitarianism, mothers and fathers are increasingly using their stereotypical conflict resolution styles as they are also inclined to do in their adult relationships.

Although not the main focus of this study, findings from our preliminary analyses regarding differences in the development of conflict resolution styles by boys and girls showed that there were some differences in the reported level of conflict resolution styles, but that there were no differences in the reported change in conflict resolution styles with mothers and fathers for boys and girls. Moreover, we found an interesting pattern of findings with respect to adolescents' and parents' mean levels on positive problem solving, conflict engagement, and withdrawal. That is, mothers and fathers reported significantly higher levels of positive problem solving and conflict engagement compared to adolescents, whereas they reported lower levels of withdrawal compared to adolescents. This pattern reflects the dominant role parents play during conflicts in early adolescence. It shows that mothers and fathers are generally more engaging in conflicts than their adolescents, either in a positive way or in a more aggressive way. Adolescents were found to use more withdrawal compared to their parents and thus withdraw more during conflicts with their parents, also demonstrating the more engaging role of parents in parentadolescent conflict. However, future research is warranted.

\section{Strengths, Limitations, and Future Directions}

The present study is the first to examine changes in conflict resolution styles in parent-adolescent relationships longitudinally from early to middle adolescence including four measurement points. Moreover, we incorporated independent reports from adolescents, mothers, and fathers. However, our study has also a number of limitations. Firstly, we used adolescents' and parents' self-reports to assess conflict resolution styles. More objective data would be obtained when using for instance observations or reports from more than one person. Secondly, although we tapped adolescents' and parents' reported changes in conflict resolution styles from early to middle adolescence, it would have been interesting to include conflict resolution styles of 
adolescents and parents during late adolescence as well. By incorporating late adolescents' and their parents' conflict resolution styles, we would for instance be able to test whether adolescents' reported level of positive problem solving with fathers change later on compared to adolescents' reported change in positive problem solving with mothers and whether fathers' reported level of positive problem solving with adolescents continues to increase into late adolescence. Also, participants in our sample were all Dutch adolescents who lived with both parents. Future research should extend our findings to other types of families, for example by including ethnic minority groups and "broken" families. Finally, although we found numerous changes in self-reported conflict resolution styles over time, the changes we found were rather small. However, this is in line with the general assumption that close relationships are inherently conservative structures that resist dramatic reformulations (Laursen and Collins 1994).

Although our study provided insight into the development of conflict resolution styles in parent-adolescent relationships, new questions arise. For example, future research might include the larger family system as well, such as conflict resolution in the sibling relationship, parent-sibling relationship, and marital relationship as this might have consequences for the way conflict is handled in families. For instance, the way parents resolve conflicts with each other has been found to influence the way adolescents handle conflicts with their parents 2 years later (Van Doorn et al. 2007). Recently, research showed that the peak in conflict frequency is sooner with second-born children than with first-born children (Shanahan et al. 2007). This might also have consequences for the way parents deal with conflicts with their second-born. Moreover, as previous research found differences in the development of compromising for the daughter-mother, daughter-father, and son-parent dyad (Jensen-Campbell and Graziano 2000), a potential next step might be to investigate changes in conflict resolution styles for all four dyads separately using a larger sample. Finally, another potential next step might be to investigate by means of multivariate growth curves whether changes in a certain conflict resolution style are accompanied by changes in other conflict resolution styles. For example, it might be interesting to test whether an increase in the use of positive problem solving by adolescents is accompanied by a decrease in conflict engagement by adolescents. Likewise, it might be interesting to investigate how the development of conflict resolution styles is related to changes in conflict intensity.

\section{Conclusions}

Taken together, our study sheds light on changes in conflict resolution styles in parent-adolescent relationships from early to middle adolescence and shows that adolescents and parents tend to change the way they handle conflict in line with the demands of a more horizontal relationship. As relationship demands change from early to middle adolescence, parents and adolescents tend to change the way they resolve conflicts with each other towards greater egalitarianism. Moreover, our results suggest that adolescent-mother relationships are mature at an earlier point in time than adolescent-father relationships, but that this maturation does not evolve without friction.

Open Access This article is distributed under the terms of the Creative Commons Attribution Noncommercial License which permits any noncommercial use, distribution, and reproduction in any medium, provided the original author(s) and source are credited.

\section{References}

Bollen, K. A. (1989). Introduction to structural equation models with latent variables. New York: Wiley.

Branje, S. J. T., van Doorn, M. D., van der Valk, I., \& Meeus, W. H. J. (2009). Parent-adolescent conflict, conflict resolution, and adolescent adjustment. Journal of Applied Developmental Psychology, 30, 195-204.

Chen, F. F. (2007). Sensitivity of goodness of fit indexes to lack of measurement invariance. Structural Equation Modeling, 14, 464-504.

Christensen, A., \& Heavey, C. L. (1990). Gender and social structure in the demand/withdraw pattern of marital conflict. Journal of Personality and Social Psychology, 59, 73-81.

Collins, W. A. (1990). Parent-child relationships in the transition to adolescence: Continuity and change in interaction, affect, and cognition. In R. Montemayor, G. R. Adams, \& T. P. Gullotta (Eds.), From childhood to adolescence: A transitional period? Advances in adolescent development (Vol. 2, pp. 85-106). Newbury Park, CA: Sage.

Collins, W. A. (1995). Relationships and development: Family adaptation to individual change. In S. Shulman (Ed.), Close relationships and socioemotional development (pp. 128-154). Norwood, NJ: Ablex.

Collins, W. A., \& Laursen, B. (2004). Parent-adolescent relationships and influences. In R. Lerner \& L. Steinberg (Eds.), Handbook of adolescent psychology (pp. 331-362). New York: Wiley.

Collins, W. A., Laursen, B., Mortensen, N., Luebker, C., \& Ferreira, M. (1997). Conflict processes and transitions in parent and peer relationships: Implications for autonomy and regulation. Journal of Adolescent Research, 12, 178-198.

Collins, W. A., \& Russell, G. (1991). Mother-child and father-child relationships in middle childhood and adolescence: A developmental analysis. Developmental Review, 11, 99-136.

Collins, W. A., \& Steinberg, L. (2006). Adolescent development in interpersonal context. In W. Damon \& N. Eisenberg (Eds.), Handbook of child psychology: Vol. 4, Socioemotional processes (pp. 1003-1067). New York: Wiley.

De Goede, I. H. A., Branje, S. J. T., \& Meeus, W. H. J. (2009). Developmental changes in adolescents' perceptions of relationships with their parents. Journal of Youth and Adolescence, 38, $75-88$.

Deković, M., Noom, M. J., \& Meeus, W. (1997). Expectations regarding development during adolescence: Parental and adolescent perceptions. Journal of Youth and Adolescence, 26, 253-272. 
Enders, C. K., \& Bandalos, D. L. (2001). The relative performance of full information maximum likelihood estimation for missing data in structural equation models. Structural Equation Modeling, 8, 430-457.

Erikson, E. H. (1959). Identity and the life cycle. New York: International University Press.

Henson, R. K. (2001). Understanding internal consistency reliability estimates: A conceptual primer on coefficient alpha. Measurement and Evaluation in Counseling and Development, 34, $177-189$.

Hu, L. T., \& Bentler, P. M. (1999). Cut-off criteria for fit indexes in covariance structure analysis: Conventional criteria versus new alternatives. Structural Equation Modeling, 6, 1-55.

Jensen-Campbell, L. A., \& Graziano, W. G. (2000). Beyond the school yard: Relationships as moderators of daily interpersonal conflict. Personality and Social Psychology Bulletin, 26, 923-935.

Keijsers, L., Frijns, T., Branje, S. J. T., \& Meeus, W. (2009). Developmental links of adolescent disclosure, parental solicitation, and control with delinquency: Moderation by parental support. Developmental Psychology, 45, 1314-1327.

Kline, R. B. (2005). Principles and practice of structural equation modeling (2nd ed.). New York: Guildford Press.

Kurdek, L. A. (1994). Conflict resolution styles in gay, lesbian, heterosexual nonparent, and heterosexual parent couples. Journal of Marriage and the Family, 56, 705-722.

Laursen, B. (1995). Conflict and social interaction in adolescent relationships. Journal of Research on Adolescence, 5, 55-70.

Laursen, B., \& Collins, W. A. (1994). Interpersonal conflict during adolescence. Psychological Bulletin, 115, 197-209.

Laursen, B., \& Collins, W. A. (2004). Parent-child communication during adolescence. In A. L. Vangelisti (Ed.), Handbook of family communication (pp. 333-348). Mahwah, NJ: Erlbaum.

Laursen, B., Coy, K. C., \& Collins, W. A. (1998). Reconsidering changes in parent-child conflict across adolescence: A metaanalysis. Child Development, 69, 817-832.

Laursen, B., Finkelstein, B. D., \& Townsend-Betts, N. (2001). A developmental meta-analysis of peer conflict resolution. Developmental Review, 21, 423-449.

Lewis, C., \& Lamb, M. E. (2003). Fathers' influences on children's development. The evidence from two-parent families. European Journal of Psychology of Education, 18, 211-228.

Meeus, W. H. J., Akse, J., Branje, S. J. T., Ter Bogt, T., Delsing, M., Van Doorn, M. D., et al. (2004). [Codebook of the research project CONflict And Management Of RElationships (CONAMORE)]. Unpublished manuscript, Utrecht University, The Netherlands.

Muthén, L. K., \& Muthén, B. O. (1998-2007). Mplus user's guide (4th ed.). Los Angeles, CA: Muthén \& Muthén.

Parke, R., \& Buriel, R. (2006). Socialization in the family: Ethnic and ecological perspectives. In N. Eisenberg (Ed.), The handbook of child psychology: Vol. 3, social, emotional, and personality development (6th ed., pp. 429-504). New York: Wiley.

Russell, A., Pettit, G. S., \& Mize, J. (1998). Horizontal qualities in parent-child relationships: Parallels with and possible consequences for children's peer relationships. Developmental Review, 18, 313-352.

Sandy, S. V., \& Cochran, K. (2000). The development of conflict resolution skills in children: Preschool to adolescence. In M. Deutsch \& P. Coleman (Eds.), The handbook of conflict resolution: Theory and practice. San Francisco: Jossey-Bass.
Selman, R. L. (1980). The growth of interpersonal understanding: Developmental and clinical analyses. New York: Academic Press.

Shanahan, L., McHale, S. M., Osgood, D. W., \& Crouter, A. C. (2007). Conflict frequency with mothers and fathers from middle childhood to late adolescence: Within- and between-families comparisons. Developmental Psychology, 43, 539-550.

Sillars, A., Canary, D. J., \& Tafoya, M. (2004). Communication, conflict, and the quality of family relationships. In A. L. Vangelisti (Ed.), Handbook of family communication (pp. 413446). Mahwah, NJ: Erlbaum.

Smetana, J. G. (1995). Parenting styles and conceptions of parental authority during adolescence. Child Development, 66, 299-316.

Smetana, J. G., Yau, J., \& Hanson, S. (1991). Conflict resolution in families with adolescents. Journal of Research on Adolescence, 1, 189-206.

Steinberg, L. (1990). Autonomy, conflict, and harmony in the family relationship. In S. S. Feldman \& G. R. Elliott (Eds.), At the threshold: The developing adolescent (pp. 255-276). Cambridge: Harvard University Press.

Tucker, C. J., McHale, S. M., \& Crouter, A. C. (2003). Conflict resolution: Links with adolescents' family relationships and individual well-being. Journal of Family Issues, 24, 715-736.

Van Doorn, M. D., Branje, S. J. T., \& Meeus, W. H. J. (2007). Longitudinal transmission of conflict resolution styles from marital relationships to adolescent-parent relationships. Journal of Family Psychology, 21, 426-434.

Van Doorn, M. D., Branje, S.J. T., \& Meeus, W. H. J. (2008). Conflict resolution in parent-adolescent relationships and adolescent delinquency. The Journal of Early Adolescence, 28, 503-527.

Videon, T. M. (2005). Parent-child relations and children's psychological well-being: Do dads matter? Journal of Family Issues, $26,55-78$.

Waizenhofer, R. N., Buchanan, C. M., \& Jackson-Newsom, J. (2004). Parents' knowledge of adolescents' daily activities: Its sources and its links with adolescent adjustment. Journal of Family Psychology, 18, 348-360.

Youniss, J., \& Smollar, J. (1985). Adolescent relations with mothers, fathers, and friends. Chicago: University of Chicago Press.

\section{Author Biographies}

Muriel D. Van Doorn is a postdoctoral researcher at Utrecht University. She received her PhD in 2008 from Utrecht University. Her research interests include adolescent relationships with parents and friends.

Susan J. T. Branje is an Associate Professor at Utrecht University. She received her $\mathrm{PhD}$ in 2003 from the Radboud University Nijmegen. Her research interests include adolescent development and the influence of parents and friends.

Wim H. J. Meeus is Professor of Adolescent Development and chair of the Research Centre of Adolescent Development at Utrecht University, The Netherlands. He received his $\mathrm{PhD}$ in 1984 from Utrecht University. His research interests include identity formation, relationships, and developmental psychopathology in adolescence. 